\title{
The impact of construction of piling partitions on the retention efficiency of a sewerage network
}

\author{
Mariusz Starzec ${ }^{1, *}$ \\ ${ }^{1}$ Rzeszow University of Technology, Department of Infrastructure and Water Management, \\ al. Powstańców Warszawy 6, 35-959 Rzeszów, Poland
}

\begin{abstract}
The aim of the article is to determine the impact of the structural solution of piling partitions of an innovative retention canals on the hydraulic conditions of its functioning in a specific sewerage network. Three types and different variants for controlling the operation of piling partitions were analyzed. The research shows that the construction of piling partitions has a significant impact on the achieved reduction rate of sewage outflow from the analyzed sewerage network. In addition, the construction of piling partitions also determines the volume of sewage that can be restored in sewer networks. The most tangible effects were observed when the partitions were made in the system (1), i.e. they had drainage holes of an adjustable geometry. In this example, a reduction in the peak sewage outflow from the sewage network to a value of only $531.36 \mathrm{dm}^{3} / \mathrm{s}$ was observed, which corresponds to the value of the wastewater reduction coefficient $\beta=0.34$. What is worth emphasizing, with the other methods of functioning of piling partitions, small values of the wastewater reduction coefficient were also obtained successively for the system (2) $\beta=0.35$, while for the system (3) $\beta=0.43$. On the basis of the tests carried out, it was also found that the authoritative time for dimensioning the sewerage network equipped with piling partitions always takes values higher than the reliable time for dimensioning a traditional sewerage network
\end{abstract}

\section{Introduction}

The consequence of progressive climate change is, among others, an increase in the amount of short-term high-intensity precipitation $[1,2]$. This forces the necessity to introduce a correction in the methodology of designing drainage systems and to take into account technical solutions that ensure high hydraulic throughput with satisfactory financial benefits [3-5]. At the same time, the objects indicated should not cause pollution of the air, water or other natural resources $[6,7]$.

When creating a concept for the expansion and modernization of operational sewerage systems [8], obstacles are encountered which are difficult to overcome, including those

\footnotetext{
* Corresponding author: mstarzec1990@prz.edu.p1
} 
related to the availability of sites that can be used for the development of sewage infrastructure $[9,10]$, and many of the solutions used so far to relieve hydraulic systems of these systems cannot be used [11].

This forces the designers to search for innovative solutions [12-14] and often change their approach to designing systems for capturing and discharging rainwater [15]. The design of individual sewer network ducts for different times of critical rainfall and assigning normative diameters to them ensures that this network works in a gravitational manner regardless of the duration of rainfall. It is worth noting, however, that the consequence of this assumption is an uneven utilization of the capacity of the designed sewerage network. In practice, this means that in the event of rain with a short duration, only the hydraulic possibilities of the initial part of the sewerage network will be used to a large extent. With the prolongation of the rainfall time, there is less use of the capacity of the initial sections of the sewerage network for the benefit of further sections.

Each drainage system has a hydraulic capacity reserve, the value of which varies with the occurrence of rainfall. What is worth emphasizing, is that the retention volume of the drainage system is in many cases significant and can contribute to eliminating the problem of occurrence of hydraulic overloads in the collectors of this system. In recent years, there has been a tendency to move away from the design of large-scale retention reservoirs to linear retention facilities [16] in the belt of a modernized or planned sewerage network. The advantages of these types of facilities is the possibility of using sewers for their construction and the lack of additional plots for investment. In addition, they require much lower costs incurred for their implementation and operation. This is due to the limitation of earthworks and often maintenance-free operation [17].

\section{Theory and calculation}

The hydraulic system of a sewage system transformed into a system of innovative retention canals was subjected to testing, adopting various methods of controlling the transport of sewage on piling partitions. Simulations were made based on the created hydrodynamic model of the adopted catchment (fig. 1), using the SWMM 5.1 hydrodynamic program. The selected rainwater sewage system consists of a total of 36 sections with a length of 120 meters each. Canal falls were assumed to be of $1.0 \%$. The total area of the drainage catchment is 144 ha, and after taking into account the runoff rate of 0.25 , the total area of the drained drainage catchment is 36 ha. Simulations were carried out using synthetic precipitation, and to determine their unitary intensity, the well-known Błaszczyk [18] formula was adopted, which determined the dependence of rainfall intensity on its duration. Simulations were carried out, measuring the average annual precipitation $H=600 \mathrm{~mm} /$ year and the incidence of precipitation $C=2$ years.

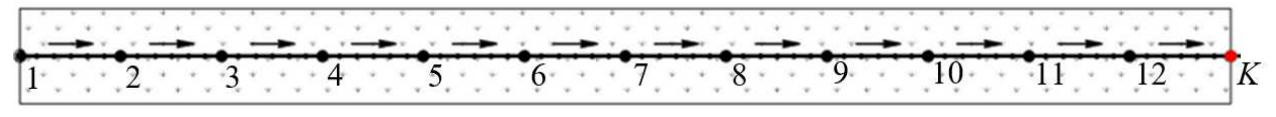

Fig. 1. Schematic of the distribution of the tested retention canals.

The analyzed sewerage network was equipped with 18 piling partitions spaced at $L_{R K}=$ $240 \mathrm{~m}$. Thus, the analyzed sewage network was transformed into 18 connected in series segments of cooperating retention chambers.

In order to determine the effect of the construction of partitions on the obtained reduction of sewage outflow in the outlet canal of the drainage catchment, different ways of piling partitions were adopted: (1) piling partitions which have a drain outlet of constant geometry and unregulated emergency overflow, (2) piling partitions which have a drainage hole with fixed geometry and an emergency overflow with an adjustable height of the 
overflow edge and (3) piling partitions which are equipped with a drainage hole with adjustable variable geometry, the change of which results in maintaining the height of the wastewater table at an optimal level.

\section{Results and discussion}

Simulation research has shown that the conversion of classical canals into a retention canal system creates favorable conditions for the effective use of the retention capacity of the network, which results in a significant, almost threefold reduction in the peak sewage outflow from the end drainage collector. The next stage of the research was to determine the efficiency of using the retention capacity of the innovative system from the applied construction of damming barriers, regulating the transport of sewage between separated retention canals.

It turns out that the most effective way of using the retention possibilities of the sewage system is the solution (3), indirect results are obtained with the method (2), while the smallest effect is characterized by the solution (1). Given the ease of implementation of the discussed solutions, this relationship is reversed. Unfortunately, the use of the retention capacity of the sewage system by method (3) requires the construction of piling partitions which are equipped with moving parts that require a power supply. However, the solution (1) has only fixed piling partitions with a determined geometry of outflow openings at the bottom of the ducts and appropriate emergency overflows.

The results of the conducted simulations using hydrodynamic modeling are presented in figure 2. Analyzing the presented graphs, it is clearly visible that the maximum sewage outflow from the analyzed rainwater sewage network was observed when it was not equipped with piling partitions regardless of the assumed rainfall duration. The peak sewage outflow from the tested sewerage network was set at $1551 \mathrm{dm}^{3} / \mathrm{s}$ and it will occur during rainfall with a duration of 41 minutes.

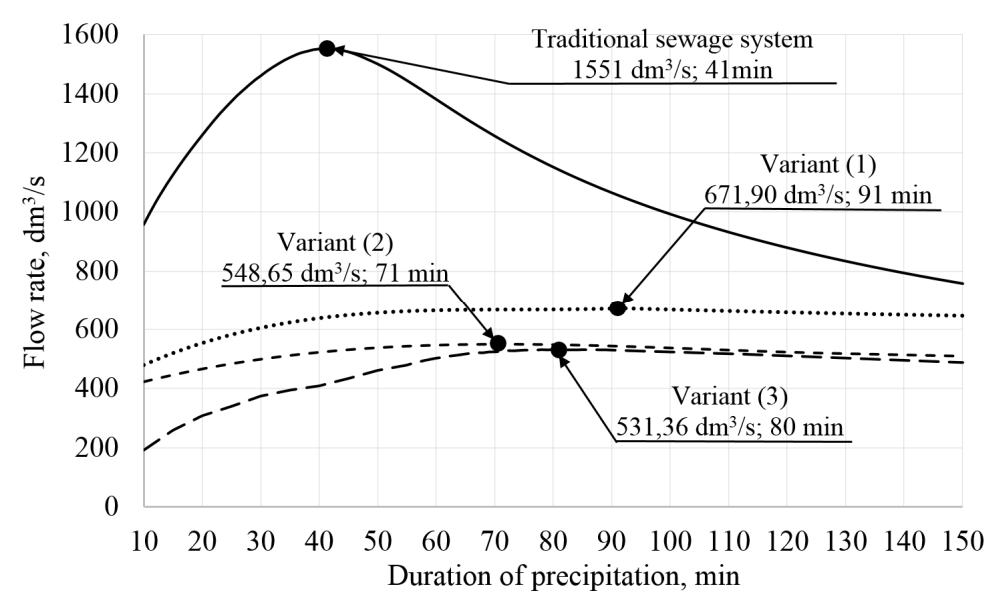

Fig. 2. The peak sewage outflow from a traditional sewage system and after the application of an innovative solution for different variants of piling partitions.

The smallest reduction in the peak sewage outflow rate from the sewage system accepted for testing was observed when the piling partitions were made in variant (1). The value of the maximum sewage outflow in this case was $671.90 \mathrm{dm}^{3} / \mathrm{s}$ during a rainfall of 91 minutes. The indirect amount of reduction of the peak sewage outflow to the value of $548.65 \mathrm{dm}^{3} / \mathrm{s}$ was observed at the piling partitions made in variant (2). It turns out that the determined reliable duration of rainfall in the analyzed case was shorter than the previous 
one and amounts to 71 minutes. However, what is noteworthy, is the highest reduction in the peak sewage outflow from the sewage network was observed after equipping it with piling partitions made according to variant (3). The peak value of sewage outflow from the catchment occurred during rainfall with a duration of 80 minutes, and its value is 531.36 $\mathrm{dm}^{3} / \mathrm{s}$.

The obtained reduction of the peak sewage outflow from the tested system of drainage canals corresponds to the value of the sewage reduction coefficient $\beta$ in the following variants: (1) of $\beta=0.43$, (2) of $\beta=0.35$ and at (3) of $\beta=0.34$.

The research results clearly show that the conversion of classically active canals into the system of retention canals allows for the effective use of canal retention, which results in a reduction of the sewage outflow from the analyzed catchment up to three times, i.e. up to $34 \%$. Differences in the reduction of the peak sewage outflow rate from $34 \%$ to $43 \%$ from the tested network depend on the utilization rate of its retention capacity.

An important originality of the conducted simulation research of cognitive significance is that it is always a reliable time for dimensioning a sewerage network equipped with piling partitions that takes on higher values than the time of reliably dimensioning a traditional sewage system.

The values of the maximum volume of sewage that can be retained in the pipelines of the tested sewerage network, depending on the adopted system of making piling partitions, which were used to prepare the graphs, are shown in figure 3.

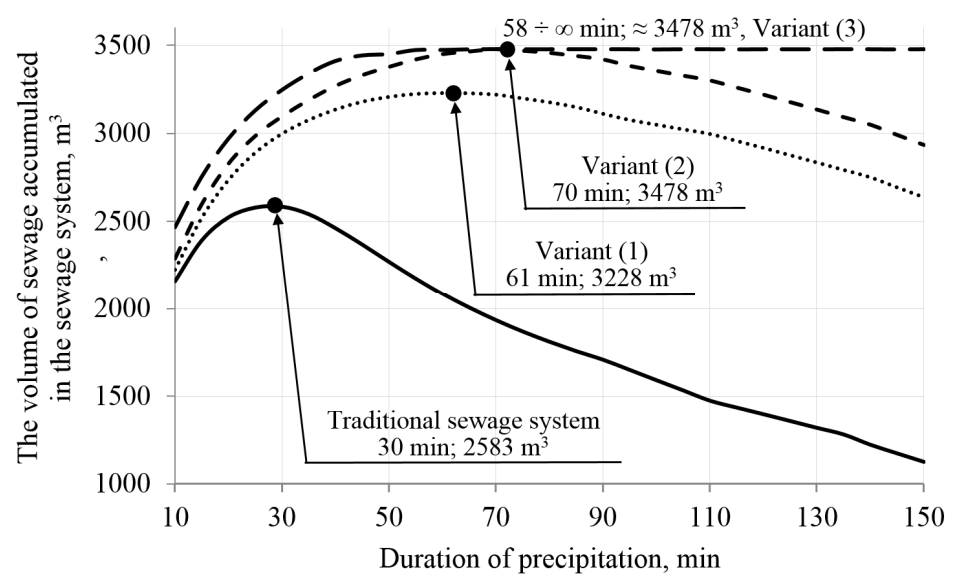

Fig. 3. Maximum volume of sewage accumulated in the pipelines of the tested sewerage network.

The graphs in figure 3 confirm the thesis that the design of piling partitions dividing the retention canals directly affects the volume of sewage volume that can be retained in the sewers. The total capacity of the analyzed sewage system is $3791 \mathrm{~m}^{3}$ and it results from the capacity of canals and wells included in its composition. In a traditional sewage network, the highest sewage volume of $2583 \mathrm{~m}^{3}$, which is retained in its sewers, was established during rain lasting 29 minutes. After equipping the sewerage network with piling partitions made in variant (1), the maximum volume of sewage stored in its collectors increased to $3228 \mathrm{~m}^{3}$, which was observed during rain lasting 61 minutes. In turn, the use of piling partitions in the variant (2) allowed for an increase in the use of the retention capacity of the sewerage network to the value of $3478 \mathrm{~m}^{3}$ with precipitation lasting 70 minutes. A special case is the functioning of retention canals with piling partitions in variant (3) equipped with a drainage hole with adjustable variable geometry. It was established that in the analyzed network transformed into a system of retention canals, their maximum retention volume is $3478 \mathrm{~m}^{3}$ and is reached with a precipitation lasting 58 minutes and with each higher rain 
duration. It was also shown that the largest volumes of retained sewage in variants (2) and (3) are equal and amount to $3478 \mathrm{~m}^{3}$.

The use of partitions with a variable geometry of outflow holes ensures a fixed maximum level of filling with sewage of successive retention canals of any designed sewerage network. Therefore, each time, with sufficiently long rainfall times, the retention capacity of the drainage system can be used to the maximum.

The developed program for the simulation of hydraulic processes occurring in the retention systems of rainwater and combined sewage systems allows for any critical cases to determine critical rainfall (reliable), at which sewage canals determined at the maximum level will occur, regardless of the adopted variant of piling partitions.

Table 1 presents the geometry of outflow openings and the height of the edge position of emergency overflows of partitions in three different variants.

Table 1. Geometry of outflow openings and the height of the edge position of emergency overflows of partitions in three different variants (1), (2) and (3).

\begin{tabular}{|c|c|c|c|c|c|c|}
\hline \multirow{2}{*}{} & & & \multicolumn{2}{|c|}{ Variant (2) } & \multicolumn{2}{|c|}{ Variant (3) } \\
\cline { 2 - 7 } & & & & \\
\hline
\end{tabular}

Since the geometry of outflow openings in variant (3) varies during the accumulation of sewage and depends on the intensity of the analyzed precipitation, therefore their geometry is not shown in Table 1. In variant (2) the height of the emergency overflow position, which is missing in Table 1 changes dynamically, which avoids the pressure of the sewerage system's ductwork. When analyzing the data contained in Table 1, it becomes obvious that successive piling partitions counting from the beginning of the sewerage network have an increasing geometry of outflow openings. 
On the basis of simulation research concerning the operation of an innovative system of retention canals, it was found that in order to obtain the greatest reduction in sewage outflow from the analyzed sewerage network, the right choice of the geometry of outflow openings is a priority. Table 2 presents three selected packages of their geometry, which were made in variant (2) based on detailed hydrodynamic simulations. The results of the tests were presented graphically in Fig. 4.

Table 2. Geometry of outflow openings of piling partitions made in variant (2).

\begin{tabular}{|c|c|c|c|}
\hline \multirow{3}{*}{$\begin{array}{l}\text { Number } \\
\text { of piling } \\
\text { partition }\end{array}$} & \multicolumn{3}{|c|}{ The diameter of the outflow opening } \\
\hline & $\begin{array}{c}\text { Example } \\
1 \\
\end{array}$ & Example 2 & Example 3 \\
\hline & {$[\mathbf{m}]$} & [m] & {$[\mathrm{m}]$} \\
\hline 1 & 0.20 & 0.21 & 0.22 \\
\hline 2 & 0.27 & 0.29 & 0.30 \\
\hline 3 & 0.33 & 0.34 & 0.36 \\
\hline 4 & 0.37 & 0.39 & 0.41 \\
\hline 5 & 0.41 & 0.43 & 0.45 \\
\hline 6 & 0.43 & 0.46 & 0.48 \\
\hline 7 & 0.46 & 0.49 & 0.51 \\
\hline 8 & 0.49 & 0.51 & 0.54 \\
\hline 9 & 0.51 & 0.54 & 0.57 \\
\hline 10 & 0.53 & 0.56 & 0.59 \\
\hline 11 & 0.55 & 0.58 & 0.61 \\
\hline 12 & 0.57 & 0.60 & 0.63 \\
\hline 13 & 0.59 & 0.62 & 0.65 \\
\hline 14 & 0.61 & 0.64 & 0.67 \\
\hline 15 & 0.63 & 0.66 & 0.69 \\
\hline 16 & 0.65 & 0.69 & 0.72 \\
\hline 17 & 0.68 & 0.72 & 0.75 \\
\hline 18 & 0.52 & 0.55 & 0.58 \\
\hline
\end{tabular}

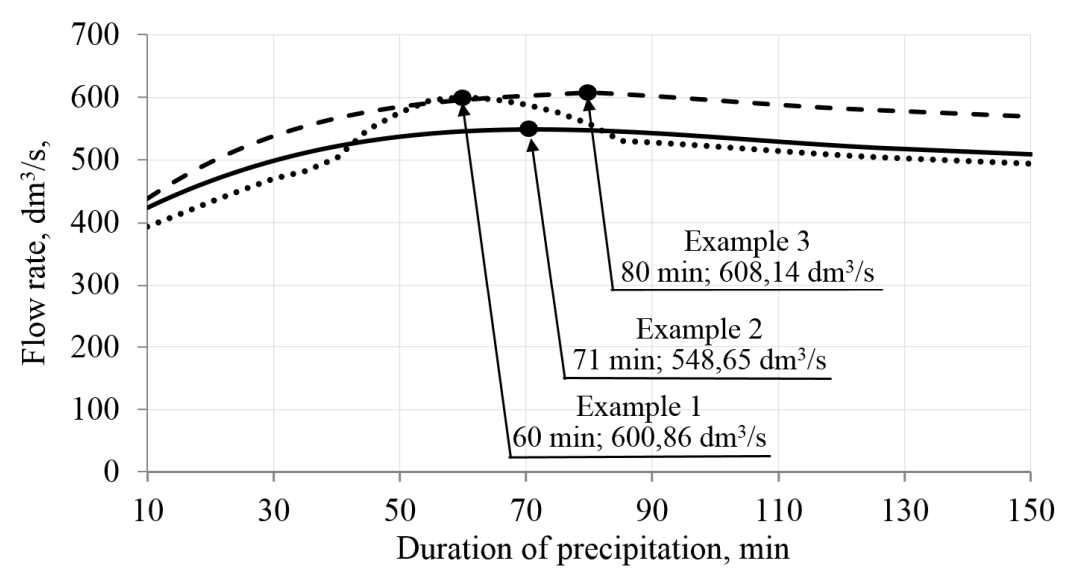

Fig. 4. The peak sewage outflow from the analyzed sewerage network at the tested outlet wall geometries of piling partitions made in variant (2). 
When analyzing the graphs presented in figure 4, it was shown that the geometry of the partition outflow openings affects the obtained reduction of the peak sewage outflow from the sewage system drainage catchment. The selection of piling partitions (example 3) of diameters that are too large results in the incomplete utilization of the retention capabilities of the analyzed sewerage network, and at the outflow a higher value of the sewage outflow rate is observed compared to the most favorable example 2. In turn, the selection of too small a drainage geometry (example 1) results in the filling of the retention canals too quickly causing frequent activation of emergency overflows and obtaining a smaller reduction of the effluent outflow in a certain range of rainfall. This situation was observed in example 1 in the range of precipitation, whose durations ranged from 43 to 82 minutes. The tests show that the optimal package of outflow diameters are the values given in example 2. It turns out that when analyzing rainfall times beyond the given range, the lowest sewage outflow occurs when the outflow geometry takes the values given in example 1 .

When designing a gravity sewer equipped with piling partitions, it is recommended to conduct an analysis of its functioning, taking into account a wide range of variable rainfall intensities respectively. This approach allows choosing an effective solution that will have the lowest possible sewage outflow from the drainage system.

\section{Conclusions}

The results of simulation research on the operation of innovative retention canals in the context of the functioning of classic sewage systems confirm the possibility of obtaining significant retention capacities of operational systems after equipping them with appropriate construction of piling partitions. The effect of controlling the size of transported sewage is in practice a significant reduction in the intensity of outgoing sewage at subsequent stages of their flow. Particularly practical significance in the implementation of the innovative system of retention canals focuses on the creation of large retention volumes of the canals, regardless of the way in which the piling partitions are tested.

It was confirmed through tests using hydrodynamic modeling that the significant effect on the obtained reduction of sewage outflow from sewage network equipped with piling partitions has a way of their implementation. The lowest reduction in sewage outflow from the sewage network was observed when the partitions were made in variant (1). On the other hand, indirect results were obtained when they were characterized by the construction in variant (2). The most tangible effects were noted when the piling partitions had a drain outlet (variant 3 ) with variable geometry.

The conducted simulation tests confirmed an important thesis of cognitive significance, namely that the duration of reliable rain for dimensioning an innovative sewerage network equipped with piling partition in each case takes values greater than the time authoritative for dimensioning the traditional sewerage network.

In addition, it was also found that the geometry of the partitions has a significant impact on the obtained reduction of the discharge effluent from the sewerage network. It has been shown that the improper selection of outflow geometry can only lead to a limited use of retention possibilities of the sewerage network. This translates into a design practice for a significantly higher intensity of sewage outflow from such a system compared to the optimal variant.

In practice, an unambiguous indication of the optimal way to build piling partitions requires a detailed analysis of the costs to be taken into account for the implementation and subsequent operation of the drainage system. Only after a thorough technical and economic analysis it would be possible to indicate a variant whose application would allow obtaining the highest benefits. 


\section{References}

1. K. Pochwat, D. Słyś, S. Kordana, J. Hydrol. 549, 501-511 (2017)

2. K. Pochwat, E3S Web Conf. 17, 00075 (2017)

3. A. Mazur, D. Słyś, E3S Web. Conf. 17, 00058 (2017)

4. A. Stec, A. Mazur, D. Słyś, E3S Web. Conf. 22, 00168 (2017)

5. S. Kordana, E3S Web Conf. 17, 00042 (2017)

6. J. Kaleta, M. Kida, P. Koszelnik, D. Papciak, A. Puszkarewicz, B. TchórzewskaCieślak, Arch. Environ. Prot. 43, 32-41 (2017)

7. L. Bartoszek, P. Koszelnik, R. Gruca-Rokosz, M. Kida, Rocz. Ochr. Sr. 17, 396-409 (2015)

8. P. S. Calabro, G. Viviani, Water Res. 40, $83-90$ (2006) 10.1016/j.watres.2005.10.025

9. D. Słyś, J. Dziopak, A. Raganowicz, Underground Infrastructure of Urban Areas 3, 253-260 (2015)

10. T. G. Schmitt, M. Thomas, N. Ettrich, J. Hydrol. 299, 300-311 (2014)

11. D. Słyś, J. Dziopak, Pol. J. Environ. Stud. 20, 743-753 (2011)

12. D. Słyś, S. Kordana, Energ. Buildings 71, 1-11 (2014)

13. Kordana, D. Słyś, J. Dziopak, J. Clean. Prod. 82, 58-69 (2014)

14. A. Stec, S. Kordana, D. Słyś, J. Clean. Prod. 151, 193-205 (2017)

15. D. Słyś, A. Stec, Ecol. Chem. Eng. S 21, 623-635 (2014)

16. M. Starzec, J. Dziopak, D. Słyś, Underground Infrastructure of Urban Areas 4, 193-200 (2018)

17. D. Słyś, A. Stec, M. Zeleňáková, Ecol. Chem. Eng. S 19, 359-372 (2012)

18. W. Błaszczyk, M. Roman, H. Stamatello, Kanalizacja TOM 1 (Arkady, Warszawa, 1974) 